\title{
Redesign Geometri Lereng Penambangan Batugamping Kuari C di PT X Kecamatan Palimanan Kabupaten Cirebon Provinsi Jawa Barat
}

\author{
Guntur Indra Prahasta*, Yuliadi \\ Prodi Teknik Pertambangan, Fakultas Teknik, Universitas Islam Bandung, \\ Indonesia. \\ *gunturip12@gmail.com,yuliadi@unisba.ac.id
}

\begin{abstract}
PT X is a cement producer which has a limestone mine in Palimanan District, Cirebon Regency, West Java Province. In the Quarry $\mathrm{C}$ limestone mining area there has been an landslide that has resulted in the inoperation of mining activities in the area. This research was conducted on the slopes of the Quarry $\mathrm{C}$ mine which had experienced a landslide. This study aims to determine the causes of landslides that occur, determine the value of cohesion, deep friction angles and safety factors when landslides occur, and recommend safe slope geometry with the input parameters results of back analysis. In this study, to determine the type of avalanche that occurs is done with stereographic projections that refer to the criteria of the landslide Hoek and Bray, 1981. Data taken in the form of strike and discontinuous dip fields using a geological compass. The initial parameter input uses physical property test data to obtain the value of natural density and mechanical properties testing, namely the shear strength test to obtain the value of cohesion and deep friction angle, as well as the compressive strength test to get the modulus young and poisson ratio values. To find out the value of cohesion, the friction angle in the safety factor during a landslide is performed back analysis using the probability method. Based on the results of data processing and data analysis conducted, it can be concluded that the landslides that occurred in section $\mathrm{C} 1$ to section $\mathrm{C} 3$ were in the form of arc slides. The results of back analysis of landslides in sections $\mathrm{C} 1$ through section $\mathrm{C} 3$ are in the form of cohesion and friction angle during landslides, namely for claystone lithology ( $\mathrm{c}=129.3 \mathrm{kPa}, \varnothing=$ $\left.25.04^{\circ}\right)$ and for Marly Limestone lithology $\left(\mathrm{c}=80.17 \mathrm{kPa}, \varnothing=11.23^{\circ}\right)$. For the recommended slope geometry in section $\mathrm{C} 1$ is $\alpha=8^{\circ}, \mathrm{H}=37.265 \mathrm{~m}$ with $\mathrm{FK}=1,299$ and section $\mathrm{C} 2$ is $\alpha=10^{\circ}, \mathrm{H}=44.712 \mathrm{~m}$ with $\mathrm{FK}=1,313$.
\end{abstract}

Keywords: Landslide, Cohesion, Friction Angle, Back Analysis, Safety Factor.

Abstrak. PT X adalah salah satu produsen semen yang mempunyai tambang batugamping di Kecamatan Palimanan, Kabupaten Cirebon, Provinsi Jawa Barat. Pada area penambangan batugamping Kuari C telah terjadi longsoran yang mengakibatkan tidak bisa beroperasinya kegiatan penambangan di area tersebut. Penelitian ini bertujuan untuk mengetahui penyebab kelongsoran yang terjadi, mengetahui nilai kohesi, sudut gesek dalam dan faktor keamanan saat terjadi longsor, serta merekomendasikan geometri lereng yang aman dengan input parameter hasil analisis balik. Pada penelitian ini, untuk mengetahui jenis longsoran yang terjadi dilakukan dengan proyeksi stereografi yang mengacu pada kriteria longsoran Hoek and Bray, 1981. Data yang diambil berupa strike dan dip bidang diskontinu menggunakan kompas geologi. Input parameter awal menggunakan data hasil pengujian sifat fisik untuk mendapatkan nilai natural density dan pengujian sifat mekanik yaitu uji kuat geser untuk mendapatkan nilai kohesi dan sudut gesek dalam, serta uji kuat tekan untuk mendapatkan nilai modulus young dan poisson ratio. Untuk mengetahui nilai kohesi, sudut gesek dalam faktor keamanan saat terjadi longsor dilakukan analisis balik dengan metode probabilitas. Berdasarkan hasil pengolahan data dan analisis data yang dilakukan, dapat disimpulkan bahwa longsoran yang terjadi pada section $\mathrm{C} 1$ sampai dengan section $\mathrm{C} 3$ berupa longsoran busur. Hasil analisis balik kelongsoran di section $\mathrm{C} 1$ sampai dengan section $\mathrm{C} 3$ berupa nilai kohesi dan sudut gesek dalam saat terjadi longsor, yaitu untuk litologi claystone $\left(\mathrm{c}=129.3 \mathrm{kPa}, \varnothing=25.04^{\circ}\right)$ dan untuk litologi Marly Limestone $(\mathrm{c}=$ $\left.80.17 \mathrm{kPa}, \varnothing=11.23^{\circ}\right)$. Untuk geometri lereng yang direkomendasikan pada section $\mathrm{C} 1$ adalah $\alpha=8^{\circ}, \mathrm{H}=$ $37.265 \mathrm{~m}$ dengan $\mathrm{FK}=1,299$ dan section $\mathrm{C} 2$ adalah $\alpha=10^{\circ}, \mathrm{H}=44.712 \mathrm{~m}$ dengan $\mathrm{FK}=1,313$.

Kata Kunci : Longsor, Kohesi, Sudut Gesek Dalam, Analisis Balik, Faktor Keamanan (FK). 


\section{A. Pendahuluan}

PT X merupakan perusahaan produsen semen di Indonesia. Saat ini PT X mempunyai 5 (lima) Kuari aktif dengan 2 (dua) area penambangan yaitu Kuari Palimanan dan Kuari Kedongdong yang memproduksi batugamping sebagai salah satu bahan baku dari semen. Kuari Palimanan dipilih sebagai lokasi penelitian karena pada lokasi ini telah terjadi longsoran yang diharuskan adanya kegiatan analisis longsoran tersebut.

Longsoran di Kuari C terjadi pada saat puncak musim hujan, hal itu diakibatkan oleh kondisi air dalam massa batuan penyusun lereng mencapai kondisi jenuh. Pada saat massa batuan berada pada kondisi jenuh nilai dari kestabilan lereng menjadi kritis. Longsoran di Kuari $\mathrm{C}$ tersebut menyebabkan kegiatan penambangan batugamping tidak beroperasi karena material longsoran mengganggu kegiatan penambangan batugamping di Kuari C.

Dengan adanya longsoran di Kuari C, diperlukan redesain lereng untuk mendapatkan geometri lereng yang stabil dan optimal agar kegiatan penambangan dapat dilakukan dengan aman kembali. Redesign dapat dilakukan dengan melakukan analisis balik untuk mencari parameter properties yang berperan sebagai faktor penyebab longsor yaitu kohesi $(\mathrm{C})$, dan sudut gesek dalam $(\Theta)$ pada saat terjadi longsor.

Berdasarkan latar belakang yang telah diuraikan, maka perumusan masalah dalam penelitian ini adalah sebagai berikut: "Bagaimana kondisi lereng di Kuari C saat terjadi longsor?, berapa nilai kohesi dan sudut gesek dalam saat terjadi longsor untuk masing-masing litologi?, Bagaimana rekomendasi geometri lereng Kuari C yang aman dan optimal?". Selanjutnya dalam penelitian ini terdapat tujuan sebagai berikut:

1. Mengetahui penyebab kelongsoran di lereng tambang Kuari $\mathrm{C}$

2. Mengetahui nilai kohesi, sudut gesek dalam, dan faktor keamanan saat terjadi longsor

3. Mengetahui dan merekomendasikan geometri lereng yang aman dan optimal dengan input parameter hasil analisis balik.

\section{B. Landasan Teori}

Pentingnya kestabilan lereng dalam suatu kegiatan penambangan terbuka akan sangat mempengaruhi kegiatan produksinya. Permasalahan kestabilan lereng ini sering ditemukan pada lereng tambang aktif, tempat penimbunan disposal, penimbunan batubara, atau lereng disekitar tambang yang lainnya. Jika lereng terbentuk sebagai akibat dari proses penambangan (pit slope) dan yang merupakan sarana penunjang operasi penambangan itu tidak stabil, kegiatan produksi terganggu dan mengakibatkan ketidaksinambungan produksi.

Menurut Gde Suratha pada tahun 1994, terdapat 5 faktor utama yang berpengaruh pada stabilitas lereng atau kelongsoran diantaranya yaitu :

1. Geometri lereng, yaitu tinggi dan kemiringan lereng.

2. Sifat fisik-mekanik, kekuatan (terutama kuat geser) dan bobot isi massa batuan pembentuk lereng.

3. Orientasi umum struktur diskontinuitas massa batuan lereng terhadap orientasi muka lereng bukaan tambang.

4. Adanya air tanah di dalam massa batuan lereng.

5. Faktor luar sistem lereng, berupa beban luar dan atau getaran (gempa bumi dan akibat peledakan tambang).

Menurut Joseph E. Bowles (2000) untuk nilai faktor keamanan harus ada batasan minimum yang dianggap sebagai batas terendah yang masih aman agar suatu lereng dapat dinyatakan stabil atau tidak. Batas minimum dari kestabilan lereng adalah sebagai berikut :

- $\mathrm{FK} \geq 1,25$ : Lereng dalam kondisi aman.

- $\mathrm{FK}<1,07$ : Lereng dalam kondisi tidak aman.

- FK 1,07 - 1,25 : Lereng dalam kondisi kritis.

Lereng yang mempunyai nilai FK tidak aman akan mengalami longsor, salah satu jenis longsor yang sering terjadi pada lereng tambang adalah longsoran busur. Longsoran busur adalah longsoran yang banyak terjadi pada lereng tambang, naik itu lereng dengan penyusun tanah atau lereng batuan yang sudah lapuk atau terkekarkan. Bentuk bidang gelincir 
pada longsoran ini membentuk busur. Untuk analisis kinematik longsoran busur dapat dilihat contohnya pada Gambar 1.

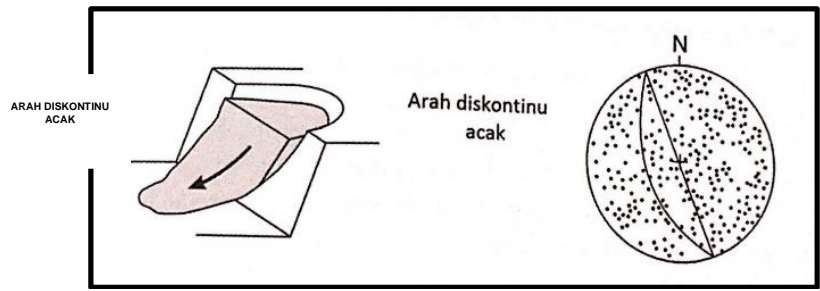

Gambar 1. Analisis Kinematik Longsoran Busur

Untuk analisis longsoran busur dapat dilakukan dengan diagram yang telah dibuat oleh Hoek and Bray (1981) namun diagram-diagram tersebut dibuat berdasarkan asumsi bahwa material penyusun lereng memiliki karakteristik yang homogen sepanjang lereng dan longsoran yang terbentuk melewati kaki lereng. Selanjutnya apabila syarat tersebut tidak memenuhi harus digunakan analisis lebih lanjut menggunakan metode irisan yang dibuat oleh Bishop (1955), Janbu (1954), Nonveiller (1965), Spencer (1967), Morgenstern and Price (1965), dan Sarma (1979).

Metode kesetimbangan batas dinyatakan dengan persamaan-persamaan kesetimbangan dari satu atau beberapa blok yang diasumsikan tidak terdeformasi, dan mengurangi gaya-gaya yang tidak diketahui (reaksi dari bagian stabil dari massa batuan atau gaya-gaya antar blok), khususnya gaya geser yang bekerja pada permukaan longsoran yang dipilih sebelumnya. Hipotesa yang dibuat secara umum adalah bahwa gaya-gaya geser ini mewakili seluruh bagian yang sama dari kuat geser batuan dimana gaya-gaya geser ini bekerja.

Kondisi kestabilan lereng dengan menggunakan metode ini dinyatakan dalam indeks faktor keamanan. Faktor keamanan dihitung menggunakan kesetimbangan gaya atau kesetimbangan momen, atau menggunakan kedua kesetimbangan gaya tersebut tergantung dari metode perhitungan yang dipakai.

Dalam menentukan faktor keamanan dengan metode ini, terdapat beberapa persamaan statis yang digunakan dalam penentuan faktor keamanan, diantaranya :

1. Penjumlahan gaya pada arah vertikal untuk setiap irisan yang digunakan untuk menghitung gaya normal pada bagian dasar irisan.

2. Penjumlahan gaya pada arah horizontal untuk setiap irisan yang digunakan untuk menghitung gaya normal antar irisan.

3. Penjumlahan momen untuk keseluruhan irisan yang bertumpu pada satu titik.

4. Penjumlahan gaya pada arah horizontal untuk irisan.

Sifat-sifat material yang relevan dengan masalah kemantapan lereng adalah sudut geser dalam $(\varnothing)$, kohesi (c), dan berat satuan $(\gamma)$ batuan. Hubungan antara kuat geser $(\tau)$ dan tegangan normal $(\sigma)$ dapat dinyatakan oleh persamaan $\tau=\mathrm{c}+\sigma$ n Tanø.

Menurut Masagus pada tahun 2011, dengan melihat beberapa kasus dan hasil penelitian terdahulu, bisa dikatakan bahwa angka FK bukanlah jaminan lereng tersebut sudah stabil, namun perlu dilihat lebih jauh dari nilai PK. Probabilitas kelongsoran lereng ditentukan dengan cara menghitung luas $(\mathrm{FK}<1)$ di bawah fungsi yang sudah ditentukan sebelumnya dari hasil proses pencocokkan. Untuk kriteria yang dapat diterima (Acceptance Criteria) probabilitas kelongsoran (probability of failure) berdasarkan Kepmen 1827 Tahun 2018 dapat dilihat pada Tabel 1.

Tabel 1. Kriteria dapat Diterima Nilai FK dan PK Berdasarkan Kepmen 1827/2018

\begin{tabular}{|c|c|c|c|c|}
\hline \multirow{2}{*}{ Jenis Lereng } & \multirow{2}{*}{$\begin{array}{c}\text { Keparahan } \\
\text { Longsor }\end{array}$} & \multicolumn{3}{|c|}{ Kriteria dapat diterima } \\
\cline { 3 - 5 } & FK Statis & FK Dinamis & $\begin{array}{c}\text { Probabilitas } \\
\text { Longsor }\end{array}$ \\
\hline Lereng Tunggal & Rendah s.d. Tinggi & 1,1 & Tidak ada & $25-50 \%$ \\
\hline \multirow{3}{*}{ Inter-Ramp } & Rendah & $1,15-1,12$ & 1 & $25 \%$ \\
\cline { 2 - 5 } & Menengah & $1,2-1,3$ & 1 & $20 \%$ \\
\cline { 2 - 5 } & Tinggi & $1,2-1,3$ & 1,1 & $10 \%$ \\
\hline \multirow{3}{*}{$\begin{array}{c}\text { Lereng } \\
\text { Keseluruhan }\end{array}$} & Rendah & $1,2-1,3$ & 1 & $15-20 \%$ \\
\cline { 2 - 5 } & Menengah & 1,3 & 1,05 & $10 \%$ \\
\cline { 2 - 5 } & Tinggi & $1,3-1,5$ & 1,1 & $5 \%$ \\
\hline
\end{tabular}


Fungsi distribusi probabilitas menggambarkan penyebaran dari suatu variabel acak yang digunakan untuk memperkirakan nilai probabilitas kemunculan suatu parameter (Gambar 2). Fungsi distribusi probabilitas memiliki sifat-sifat penyebaran yang khas dan unik menjadikan fungsi yang satu akan berbeda dengan fungsi yang lainnya (Masagus, dkk, 2011).

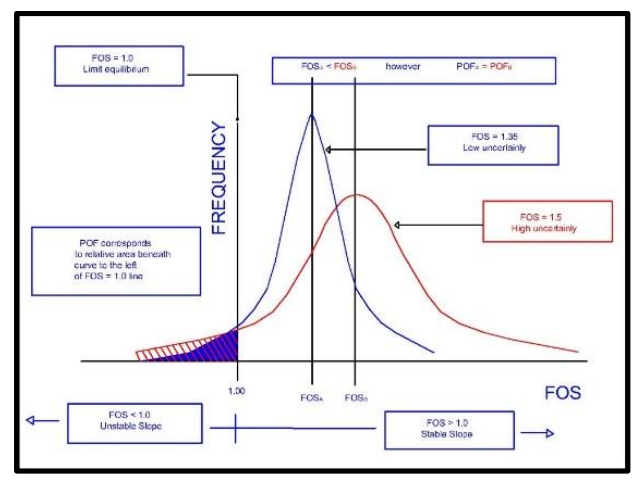

Gambar 2. Konsep Probabilitas Kelongsoran:

\section{Hasil Penelitian dan Pembahasan}

Pengumpulan data geoteknik ini pada tambang batugamping PT Indocement Tunggal Prakarsa ini meliputi pemetaan geoteknik, pengamatan model kelongsoran yang terjadi, dan sampling boulder untuk uji point load di laboratorium. Studi geoteknik ini dilakukan karena adanya kelongsoran pada lereng Kuari C.

Pemetaan geoteknik ini bertujuan untuk mendapatkan informasi mengenai kondisi massa batuan guna menentukan parameter kekuatannya. Pemetaan geoteknik ini difokuskan pada kelompok massa batuan lereng Kuari C, yang terdiri dari lapisan lempung dan lapisan batugamping yang masih memungkinkan untuk dijangkau dan dipetakan. Data yang didapat dari pemetaan ini meliputi strength index, RQD, joint spacing, joint conditions, dan orientasi bidang diskontinuitas (struktur). Lokasi pemetaan geoteknik yang berhasil dijangkau dan dianggap cukup mewakili kondisi di Kuari C yaitu CP1, DP1, DP2. Dari hasil pemetaan geoteknik pada masing-masing titik pengamatan scanline yang dilakukan pada CP1, DP1, DP2, A'P1 yang mempunyai kelas massa batuan Fair Rock. Setelah dilakukan pembobotan Rock Mass Rating untuk mengetahui kelas masa batuan, didapatkan kelas masa batuan Fair Rock menandakan bahwa kekuatan batuan tersebut masih dalam kondisi yang fair atau sedang. Hasil dari pembobotan ini akan dijadikan sebagai acuan dalam menganalisis stabilitas lereng.

Bidang diskontinu dalam massa batuan dapat membantu mudahnya proses penggalian serta keberadaan bidang diskontinu dalam massa batuan dapat membantu pencapaian fragmentasi yang diinginkan. Namun dari sisi geoteknik keberadaan bidang diskontinu ini akan mempengaruhi dari stabilitas lereng.

Berdasarkan hasil pengamatan dan pengukuran kondisi bidang diskontinu pada Kuari C yang meliputi jarak antar kekar serta longsoran yang terjadi di Kuari C, selanjutnya dilakukan korelasi antara jenis longsoran yang terjadi di lapangan dan juga analisis potensi ketidakmantapan lereng tambang. Secara grafis, hasil pengukuran orientasi bidang diskontinu diplot dengan menggunakan streonet dan hasilnya menunjukan bahwa kekar pada scanline A'P1 menunjukan bahwa berpotensi menghasilkan longsoran busur, kekar pada scanline CP1 menunjukan bahwa berpotensi menghasilkan longsoran busur, kekar pada scanline DP1 menunjukan bahwa berpotensi menghasilkan longsoran busur, kekar pada scanline DP2 menunjukan bahwa berpotensi menghasilkan longsoran busur.

Hasil analisis potensi longsoran ini akan digunakan sebagai acuan dalam melakukan simulasi analisis stabilitas lereng agar hasilnya lebih akurat dan mendekati keadaan 
sebenarnya, selain itu untuk hasil analisis potensi longsoran ini bisa digunakan dalam kegiatan pengubahan arah penambangan.

Pengeboran geoteknik ini dilakukan dengan metode full coring yang bertujuan untuk mengambil sampel batuan yang berada dibawah permukaan. Sampel batuan yang telah diambil akan dilakukan pengujian untuk mengetahui sifat fisik dan sifat mekanik dari batuan.

Dalam penentuan titik pengeboran geoteknik harus mempertimbangkan kondisi geologi wilayahnya serta mempertimbangkan ultimate pit limit. Pengeboran di PT Indocement Tunggal Prakarsa dilakukan pada 4 titik yaitu titik GT-01, GT-02, GT-03, GT-04. Namun lokasi pengeboran yang dianggap mewakili pada daerah penelitian adalah GT-01, GT-02 saja.

Dari kegiatan hasil pengeboran batuan yang selanjutnya akan dilakukan uji sifat fisik dan uji sifat mekanik batuan. Dari hasil pengujian sifat fisik didapatkan nilai natural density untuk lithologi claystone sebesar 0,0206-0,0207 MN/m3, limestone sebesar 0,283 - 0,285 MN/m3, Lime-Marly sebesar 0,0272 MN/m3, Lime-Rich sebesar 0,0286 MN/m3, Clay-Rich sebesar $0,0214 \mathrm{MN} / \mathrm{m} 3$.

Dari hasil pengujian kuat geser didapatkan nilai kohesi (C) dan sudut gesek dalam ( $\Theta$ ) untuk lithologi claystone $\mathrm{C}=0,312-0.156 \mathrm{MPa}$ dan $\Theta=26,96^{\circ}-27,89^{\circ}$, limestone $\mathrm{C}=0,233$ - 0,235 MPa dan $\Theta=36,88^{\circ}$, Lime-Marly $\mathrm{C}=0,269 \mathrm{MPa}$ dan $\Theta=34,32^{\circ}$, Lime-Rich $\mathrm{C}=$ $0,236 \mathrm{MPa}$ dan $\Theta=35,89^{\circ}$, dan Clay-Rich $\mathrm{C}=0,151 \mathrm{MPa}$ dan $\Theta=29.74^{\circ}$.

Dari hasil pengujian kuat tekan didapatkan nilai Modulus Young dan Poisson Ratio untuk lithologi claystone 4125,35 - 1839,16 MPa dan 0,26 - 0,27, limestone 356,54 MPa dan 0,23, Lime-Marly 12842,47 MPa dan 0,24, Lime-Rich 6471,91 MPa dan 0,23, dan Clay-Rich 571,96 MPa dan 0,29.

\section{Analisis Lereng Keseluruhan}

Analisis kemantapan lereng keseluruhan bertujuan untuk menentukan tingkat kemantapan suatu lereng dengan membuat model pada sudut dan tinggi tertentu. Analisis kemantapan lereng ini menggunakan acuan input parameter hasil uji lab untuk litologi claystone unit weight $0,0207 \mathrm{MN} / \mathrm{m}^{3}$, sudut gesek dalam $26,96^{\circ}$, kohesi $0,156 \mathrm{Mpa}$. Lime-Marly unit weight 0,0272 $\mathrm{MN} / \mathrm{m}^{3}$, sudut gesek dalam $34,32^{\circ}$, kohesi $0,269 \mathrm{Mpa}$. Untuk section $\mathrm{C} 1$ dengan geometri ketinggian $61,158 \mathrm{~m}$ dengan kemiringan $13^{\circ} \mathrm{FK}=1,605$, section $\mathrm{C} 2$ dengan geometri ketinggian 64,3 $\mathrm{m}$ dengan kemiringan $14^{\circ} \mathrm{FK}=2,06$, Section $\mathrm{C} 3$ dengan geometri ketinggian $34,18 \mathrm{~m}$ dengan kemiringan $17^{\circ} \mathrm{FK}=1,545$.

\section{Analisis Balik Lereng Tambang}

Analisis kelongsoran pada section $\mathrm{C} 1$ sampai dengan section $\mathrm{C} 3$ dilakukan pada section $\mathrm{C} 2$ karena pada section ini berada pada tengah bidang longsoran serta pada analisis awal mempunyai FK paling besar sehingga dianggap cukup mewakili untuk menganalisis permasalahan kelongsoran lereng Kuari C. Menganalisis kondisi lereng sebelum terjadi longsor (lereng desain) dan selanjutnya dilakukan analisis balik (back analysis) dengan input parameter hasil uji laboratorium. Melakukan analisis balik dengan input parameter bobot isi, kohesi dan sudut gesek dalam. Kemudian mensimulasikannya sebanyak 1000 kali dengan interval kohesi dan sudut gesek dalam. Interval yang digunakan dalam analisis balik ini antara lain untuk litologi claystone : interval kohesi $1147-2800 \mathrm{kPa}$, standar deviasi kohesi 55,2 kPa, Interval

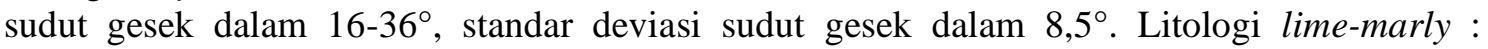
interval kohesi $70-170 \mathrm{kPa}$, standar deviasi kohesi 41,2 $\mathrm{kPa}$, Interval sudut gesek dalam 32,8 $8^{\circ}$, standar deviasi sudut gesek dalam $8^{\circ}$. Dengan nilai $\mathrm{FK}=0,942$ dengan nilai probabilitas kelongsoran $42,8 \%$. Dari hasil analisis balik section C2 ini berupa grafik hubungan antara kohesi dengan sudut gesek dalam dan grafik hubungan antara sudut gesek dalam dengan faktor keamanan untuk masing-masing litologi pada input parameter awal seperti pada gambar berikut ini : 


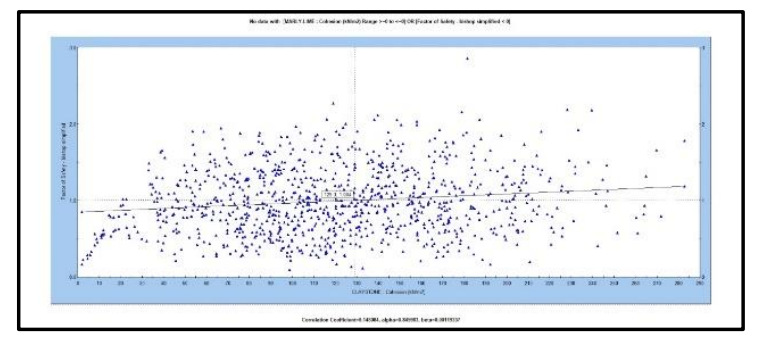

Gambar 3. Grafik Hubungan Kohesi dengan FK (Claystone)

Pada grafik hubungan antara kohesi dengan FK untuk litologi claystone didapatkan persamaan linear $\mathrm{y}=0,0007 \mathrm{x}+0,8459$, sehingga dapat disimpulkan bahwa kohesi claystone untuk mencapai $\mathrm{FK}=1$ adalah $129.3 \mathrm{kPa}$

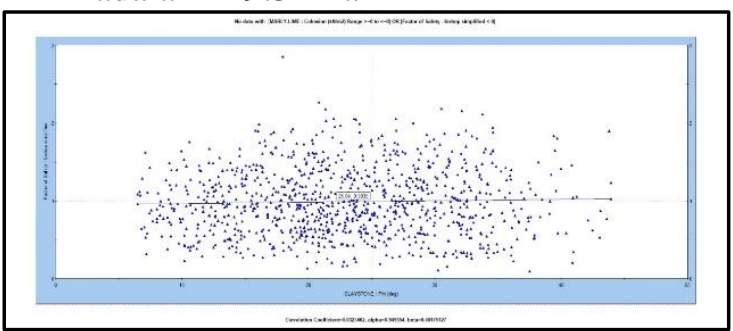

Gambar 4. Grafik Hubungan Sudut Gesek Dalam dengan FK (Claystone)

Pada grafik hubungan antara sudut gesek dalam dengan FK untuk litologi claystone didapatkan persamaan linear $\mathrm{y}=0,0027 \mathrm{x}+0,9493$, sehingga dapat disimpulkan bahwa sudut gesek dalam claystone untuk mencapai $\mathrm{FK}=1$ adalah $25.04^{\circ}$.

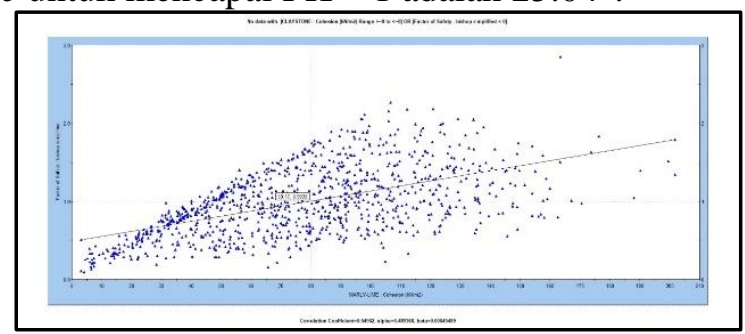

Gambar 5. Grafik Hubungan Kohesi dengan FK (Lime-marly)

Pada grafik hubungan antara kohesi dengan FK untuk litologi limestone didapatkan persamaan linear $\mathrm{y}=0,0089 \mathrm{x}+0,4893$, sehingga dapat disimpulkan bahwa kohesi Marly Limestone untuk mencapai $\mathrm{FK}=1$ adalah $80.17 \mathrm{Kpa}$.

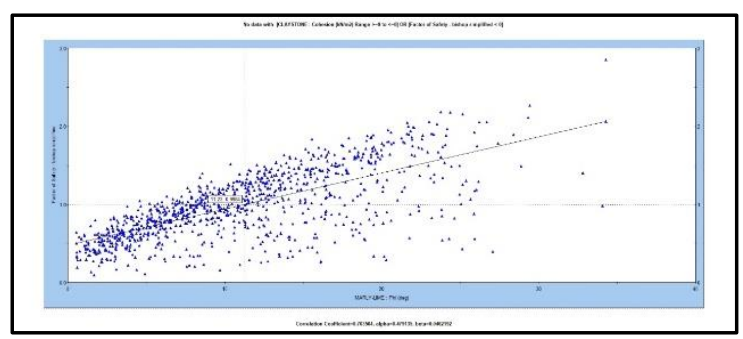

Gambar 6. Grafik Hubungan Sudut Gesek Dalam dengan FK (Lime-marly)

Pada grafik hubungan antara sudut gesek dalam dengan FK untuk litologi limestone didapatkan persamaan linear $\mathrm{y}=0,0462 \mathrm{x}+0,4791$, sehingga dapat disimpulkan bahwa sudut gesek dalam Marly Limestone untuk mencapai FK $=1$ adalah $11.23^{\circ}$. 


\section{Analisis Kestabilan Lereng dengan Input Parameter Hasil Analisis Balik}

Analisis kestabilan lereng dengan input parameter hasil analisis balik untuk section $\mathrm{C} 1$ dengan geometri ketinggian $61,158 \mathrm{~m}$ dengan kemiringan $13^{\circ} \mathrm{FK}=0,898$, section $\mathrm{C} 2$ dengan geometri ketinggian $64,3 \mathrm{~m}$ dengan kemiringan $14^{\circ} \mathrm{FK}=0,943$, Section $\mathrm{C} 3$ dengan geometri ketinggian $34,18 \mathrm{~m}$ dengan kemiringan $17^{\circ} \mathrm{FK}=1,282$. Dari analisis stabilitas lereng keseluruhan section $\mathrm{C} 1$ dan section $\mathrm{C} 2$ menghasilkan nilai $\mathrm{FK} \leq 1,25$, sehingga harus dilakukan desain kembali (redesign) dengan menggunakan geometri baru. Sedangkan Section C3 mempunyai nilai FK $\geq$ 1,25 maka C3 tidak akan dilakukan redisgn.

Analisis Stabilitas Redesign Geometri Lereng Keseluruhan

Analisis kestabilan lereng dengan input parameter hasil analisis balik untuk section $\mathrm{C} 1$ dengan geometri hasil redesign ketinggian 37,265 m dengan kemiringan $8^{\circ} \mathrm{FK}=1,299$, seperti pada Gambar 7.

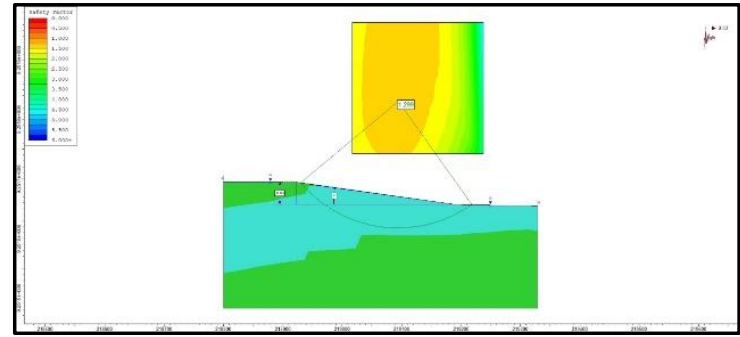

Gambar 7. Rekomendasi Geometri lereng section C1

Untuk section C2 dengan geometri redesign ketinggian 44,712 m dengan kemiringan $10^{\circ} \mathrm{FK}=1,313$, seperti pada Gambar 8.

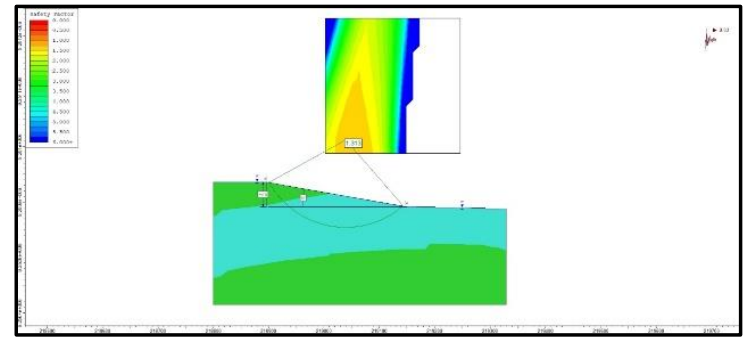

Gambar 8. Rekomendasi Geometri lereng section C2

Pada lereng batuan Kuari C terdapat banyak struktur kekar yang berkembang. Struktur kekar diindikasikan sebagai salah satu faktor penyebab terjadinya kelongsoran pada lereng Kuari $\mathrm{C}$ karena besar nilai gaya-gaya pada batuan tersebut yang mengakibatkan terganggunya kestabilan lereng dan pada akhirnya dapat menyebabkan lereng tersebut longsor.

Berdasarkan hasil pengukuran scanline yang dilakukan disekitar lereng Kuari C, didapatkan kelas massa batuan Fair Rock yang menandakan bahwa kekuatan batuan tersebut masih dalam kondisi yang fair atau sedang dengan keadaan lereng yang lembab atau lereng dalam keadaan jenuh yang menambah kemungkinan untuk terjadinya suatu kelongsoran.

Berdasarkan hasil analisis kinematik menggunakan proyeksi stereografi, longsoran yang mungkin terjadi pada lereng tambang Kuari $\mathrm{C}$ ini adalah jenis longsoran busur dimana longsoran busur ini akan terjadi pada lereng batuan yang lemah, terkekarkan dan jenuh.

penanganan lereng yang mengalami kelongsoran harus segera ditangani agar kegiatan penambangan dapat kembali dilakukan.

Dalam kegiatan analisis balik ini dilakukan dengan memodelkan kembali lereng kondisi geometri lereng aktual dengan menggunakan metode kesetimbangan batas (Limit Equilibrium Method, LEM). Pembagian segmen pada lereng dengan pusat gaya pada titik tertentu dilakukan pada metode ini. Setelah itu gaya yang bekerja pada sebuah lereng akan dianalisis saat terjadinya kelongsoran pada lereng tersebut.

Hasil dari analisis kestabilan lereng merupakan nilai FK yang akan digunakan sebagai acuan untuk menentukan lereng tersebut stabil atau tidak. Menurut Joseph E. Bowles, lereng 
dikatakan aman apabila mempunyai nilai strength to stress ratio atau Faktor Keamanan mencapai lebih besar dari 1,25 atau dengan kata lain perbandingan antara nilai kekuatan batuan harus lebih besar daripada nilai gaya yang bekerja pada setiap elemen model sesuai dengan kriteria keruntuhan yang digunakan.

Pada lereng tambang yang telah mengalami longsor, harus segera dilakukan desain ulang pada lereng tersebut agar kegiatan penambangan dapat segera dilakukan kembali. Penyebab longsoran pada suatu lereng tambang salah satunya adalah nilai dari sifat mekanik batuan penyusun lereng tersebut diantaranya adalah kohesi dan sudut gesek dalam. Untuk mengetahui nilai kohesi dan sudut gesek dalam saat terjadinya longsor adalah dengan cara analisis balik.

Pada studi ini, dilakukan menggunakan analisis balik dengan analisa probabilitas. Dengan menggunakan analisa probabilitas dapat menggambarkan sebaran suatu variabel secara acak yang nantinya akan digunakan dalam mendapatkan nilai probabilitas kemunculan suatu parameter. Selain itu, analisa probabilitas ini akan memunculkan nilai kohesi dan sudut gesek dalam baru pada nilai faktor keamanan yang aman.

Analisa probabilitas akan mengiterasi data input parameter awal sebanyak 1000 kali dan dari hasil iterasi data tersebut dalam bentuk grafik perbandingan hubungan antara nilai kohesi dengan nilai faktor keamanan dan grafik perbandingan antara nilai sudut gesek dalam dengan faktor keamanan yang nantinya akan didapatkan nilai kohesi dan sudut gesek dalam yang baru pada saat terjadi longsor. Nilai input parameter baru tersebut diasumsikan mewakili nilai parameter massa batuan penyusun lereng yang sebenarnya.

Input parameter baru ini selanjutnya akan digunakan untuk menganalisis lereng dengan geometri aktual sebelum terjadi longsor. Nilai faktor keamanan harus mempunyai nilai $\geq 1,25$ agar dianggap aman dan tidak dilakukan desain ulang pada lereng tersebut. Apabila nilai faktor keamanan FK $\leq 1,25$ maka dilakukan desain ulang karena dianggap mengalami longsor. Hasil analisis stabilitas lereng aktual section $\mathrm{C} 1$ dan section $\mathrm{C} 2$ tersebut didapat nilai faktor keamanan yang tidak aman atau faktor kemanan $\leq 1,25$, sehingga harus dilakukan desain kembali (redesign) dengan menggunakan geometri baru. Sedangkan untuk section C3 mempunyai nilai faktor kemanan $\geq 1,25$ yang dianggap aman sehingga tidak dilakukan desain ulang.

Terjadinya longsor pada Kuari C section C1 s.d. C3 dengan dimensi longsoran yang besar diasumsikan faktor utama penyebab kelongsoran itu adalah geometri lereng diantaranya kemiringan lereng aktual sebelum longsor yang curam dan melebihi kemiringan desain yang direkomendasikan, penyebab lain adalah faktor air hujan yang menyebabkan batuan penyusun lereng mencapai pada titik jenuh sehingga menambah beban yang berati gaya pendorong pada lereng semakin besar dan membuat kemungkinan semakin tinggi untuk terjadinya longsor, selain itu penyebab lain dari longsornya lereng tambang Kuari $\mathrm{C}$ adalah terlambatnya kegiatan penggalian di bagian atas, sementara penggalian di bagian tengah-bawah sudah melewati desain.

\section{Kesimpulan}

Berdasarkan pembahasan dalam penelitian ini, peneliti menyimpulkan beberapa hasil penelitian sebagai berikut:

Berdasarkan hasil penelitian yang telah dilakukan, analisis dan pemodelan kemantapan lereng yang disimulasikan maka dapat diambil kesimpulan sebagai berikut.

1. Longsornya lereng tambang Kuari $\mathrm{C}$ diduga karena pada lapisan batuan terdapat bidang diskontinu yang berkembang pada lereng Kuari C. Selain itu diakibatkan juga oleh keadaan lereng yang lembap atau diindikasikan lereng dalam keadaan jenuh yang menambah kemungkinan untuk terjadi longsor.

2. Berdasarkan analisis balik yang dilakukan terhadap kelongsoran di section C1 s.d. C3 didapatkan nilai kohesi dan sudut gesek dalam batuan baru hasil analisis balik, yaitu untuk litologi claystone $\left(\mathrm{c}=129,3 \mathrm{kPa}, \varnothing=25,04^{\circ}\right)$, Marly Limestone $(\mathrm{c}=80,17 \mathrm{kPa}$, $\varnothing=11,23^{\circ}$ ). Dari hasil analisis balik ini diketahui bahwa nilai FK pada saat terjadi 
longsor untuk section $\mathrm{C} 1$ adalah 0,898 dan untuk section $\mathrm{C} 2$ adalah 0,943 . Sedangkan untuk section C3 mempunyai FK 1,282 yang dianggap aman sehingga tidak dilakukan redesign.

3. Rekomendasi geometri untuk section $\mathrm{C} 1\left(\alpha=8^{\circ}, \mathrm{H}=37,265 \mathrm{~m}, \mathrm{FK}=1,299\right)$ dan untuk section $\mathrm{C} 2\left(\alpha=10^{\circ}, \mathrm{H}=44,712 \mathrm{~m}, \mathrm{FK}=1,313\right)$

\section{E. Saran}

1. Dalam pembuatan lereng tunggal atau lereng keseluruhan jangan mengabaikan rekomendasi dari hasil kajian geoteknik

2. Jangan melakukan kegiatan penggalian melewati batas dari desain

3. Segera melakukan kegiatan pemindahan material longsoran agar kegiatan penambangan dapat dilakukan kembali.

\section{Daftar Pustaka}

[1] Anonim, 2013, "Kajian Geoteknik dan Hidrogeologi Untuk Quarry Batukapur di Pabrik Palimanan, Cirebon" LAPI Institut Teknologi Bandung: Bandung.

[2] Anonim, 2018. "Pedoman Pelaksanaan Kaidah Penambangan yang Baik" Kementrian Energi Sumber Daya Mineral, Jakarta.

[3] Ahmad, Masagus A., dkk, 2011, "Aplikasi Probabilistik Untuk Analisis Kestabilan Lereng Tunggal (Studi Kasus Di PT. Tambang Batubara Bukit Asam Tbk. Tanjung Enim, Sumatera Selatan)", Prosiding TPT XX PERHAPI, Mataram.

[4] Arif, Irwandy, 2016, "Geoteknik Tambang”, Institut Teknologi Bandung: Bandung.

[5] Bienawski, Z.T., 1989, "Engineering Rock Mass Classifications: A Complete Manual for Engineers and Geologists in Mining, Civil, and Petroleum Engineering", WilleyInterscience.

[6] Bhafikatti, SS. 2005. "Finite Element Analysis. New age international". New Delhi.

[7] Bowles, J.E., 1984, "Physical and Geotechnical Properties of Soil 2nd Ed", Me Graw-Hill Inc.

[8] Fredlund, D.G., J. Krahn dan D.E. Pufahl. 2004. "The Relationship between Limit Equilibrium Slope Stability Method. Dept. of Civil Engineering, University of Saskatchewan, Saskatoon, Canada.

[9] Hoek, E., Bray, J. W., 1981, "Rock Slope Engineering", Institution of Mining and Metallurgy, London.

[10] Pathak S., Poudel R.L., Kansakar B.R., 2006, "Application of Probabilistic Approach in Rock Slope Stability Analysis - an Experience from Nepal, pp. 797-802”, Universal Academy Press, Inc. - Tokyo, Japan.

[11] Romana, M., Seron, J.B., Montalar, E., 2003. "SMR Geomechanics Classification for Slopes: Slope Mass Rating", Comprehensive Rock Engineering, Editor: Hudson, J.A. Pergamon.

[12] Suratha, Gde., 1994, "Kemantapan Lereng", Direktorat Jenderal Pertambangan Umum Pusat Pengembangan Tenaga Pertambangan, Bandung.

[13] Tapia, A., Contreras, L.F., Jefferies, M.G., And Steffen O. 2007. "Risk Evaluation of Slope Failure at Chuquicamata Mine" Proc. Int. Symp. Rock Slope Stability in Open Pit Mining and Civil Engineering, 2007. Perth. Australian Centre for Geomechanics 